\title{
Endodontic Management of Dens Evaginatus Using Bioceramic Material
}

\author{
Kranthi R Kacharaju ${ }^{1}$, Nazmul Haque ${ }^{2}$, Padmini Hari ${ }^{3}$, Kiran P Singbal ${ }^{4}$
}

\begin{abstract}
Aim: This case report aims to describe nonsurgical endodontic treatment in a second mandibular premolar (tooth \#45) with type II dens evaginatus using a new bioceramic material (OrthoMTA).

Background: A 13-year-old boy reported recurrent swelling related to mandibular premolars (\#44 and \#45) with discharging sinus in the periapical area.

Case description: Orthograde obturation with OrthoMTA was done after thorough disinfection using activated sodium hypochlorite (NaOCl) and calcium hydroxide $\left(\mathrm{Ca}(\mathrm{OH})_{2}\right)$ medicament.

Conclusion: A 1-year post-obturation follow-up, using clinical and radiographic examination [cone-beam computed tomography (CBCT)] showed good apical sealing.

Clinical significance: The synergistic effect of the chemomechanical preparation and intracanal medicament, followed by the filling of OrthoMTA helped, in the successful management of this case.

Keywords: Bioceramics, Cone-beam computed tomography, Dens evaginatus, Mandibular premolar, OrthoMTA.

World Journal of Dentistry (2019): 10.5005/jp-journals-10015-1682
\end{abstract}

\section{BACKGROUND}

Dens evaginatus is a rare odontogenic developmental anomaly that results in the abnormal morphological presentation of the dental tissues. It is also known as a tuberculated cusp, accessory tubercle, tuberculum dentis, occlusal tuberculated premolar, crown tubercle, tuberculum coronae, leong's premolar, evaginatus odontoma, and occlusal pearl., ${ }^{1,2}$ Prevalence of this pathological condition varies between races and ethnic groups, with a higher prevalence in the people from mongoloid origin while it is rare among the Caucasians. ${ }^{3,4}$ This indicates the involvement of genetic factors in the pathogenesis of this disease. ${ }^{5}$ Moreover, the prevalence of this is more in males compared to females. ${ }^{2}$ Usually, the posterior teeth, often the premolars are affected by dens evaginatus, followed by the molars. ${ }^{6}$

The etiology of dens evaginatus is not clear yet. Several researchers have identified it as an anomaly during the developmental stage of the teeth that could occur because of unusual proliferation and folding of the inner enamel epithelium lining the stellate reticulum of the enamel organ. ${ }^{7,8}$ The cusp-like protrusion on the occlusal surface of the evaginated tooth may or may not contain the pulp. However, the wear or fracture of the cusp because of malocclusion, if untreated, may lead to pulpal exposure followed by necrosis. ${ }^{5,6}$ If the pulp becomes inflamed or necrotic, endodontic therapy and/or regenerative endodontic procedure are considered the suitable treatment option.

In recent years, dentists are embracing bioceramic materials for root canal obturation because of their antibacterial, bioactive, and regenerative properties. This report aims to describe the management of a mandibular second premolar tooth with dens evaginatus and necrotic pulp using a new bioceramic material (OrthoMTA).

\section{Case Description}

\section{Case History}

A 13-year-old boy reported to the Department of Conservative Dentistry and Endodontics, MAHSA University, with a chief

\footnotetext{
1,4Department of Conservative Dentistry, Faculty of Dentistry, MAHSA University, Selangor, Malaysia

${ }^{2}$ Department of Oral Biology and Biomedical Sciences, Faculty of Dentistry, MAHSA University, Selangor, Malaysia

${ }^{3}$ Department of Periodontology, Faculty of Dentistry, MAHSA University, Selangor, Malaysia
}

Corresponding Author: Kranthi R Kacharaju, Department of Conservative Dentistry, Faculty of Dentistry, MAHSA University, Selangor, Malaysia, Phone: +60 166590480, e-mail: kranthi@mahsa. edu.my

How to cite this article: Kacharaju KR, Haque N, Hari P, et al. Endodontic Management of Dens Evaginatus Using Bioceramic Material. World J Dent 2019;10(6):461-465.

Source of support: Nil

Conflict of interest: None

complaint of swelling on the right lower back region of the jaw between first (\#44) and second (\#45) mandibular premolars. Patient informed that the swelling started 3 months ago. The swelling subsided temporarily after he visited a dentist who prescribed him antibiotics. The swelling recurred after 1 month.

\section{Clinical Examination}

Clinical examination revealed a $4 \times 4 \mathrm{~mm}$ swelling with a discharging sinus on the buccal mucosa in-between tooth \#44 and \#45 (Fig. 1A). Both teeth were sound with an occlusal facet on 45 (Fig. 1C). An electric pulp testing diagnosed tooth \#45 as nonresponsive, while \#44 had a positive response. To trace the origin of the sinus, a guttapercha point was inserted, and a radiograph was taken (Fig. 1B).

The intraoral periapical (IOPA) radiograph revealed the guttapercha leading to the radiolucency involving the mesial surface of the root of \#45 up to the apex (Fig. 1D). Cone beam computed tomography (CBCT) was further performed in order to visualize the 

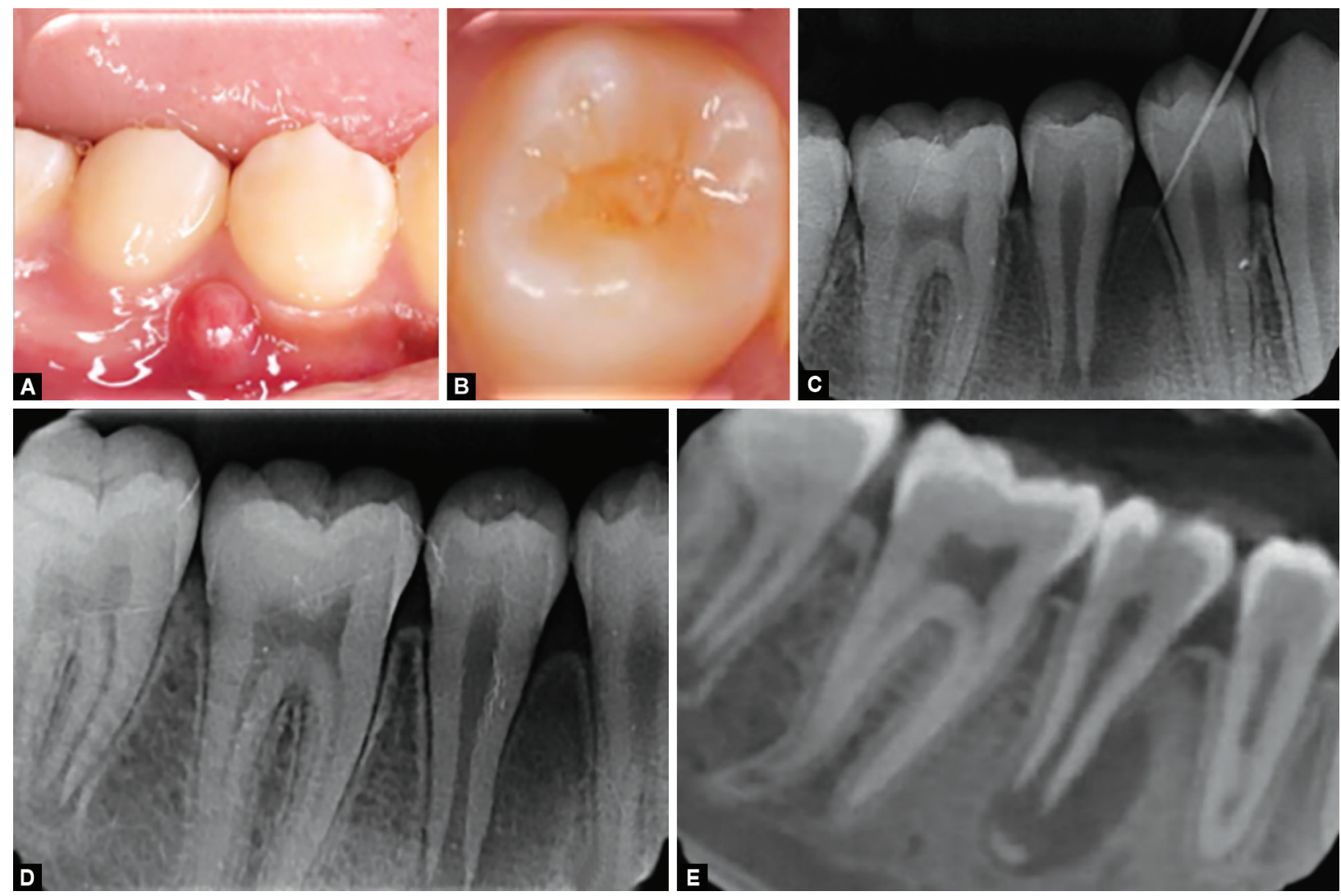

Figs $1 \mathrm{~A}$ to E: (A) Clinical picture showing a swelling in-between tooth \#44 and \#45; (B) Occlusal view of tooth \#45; (C) Tracing the origin of the sinus using gutta-percha; (D) Diagnostic intraoral periapical (IOPA) radiograph of tooth \#45 during 1st visit; (E) Cone-beam computed tomography (CBCT) scan of tooth \#45 during 1st visit

full extent of the lesion. The $\mathrm{CBCT}$ imaging showed an extensive bone loss on the buccal and mesial of tooth \#45 (Fig. 1E). After the investigations, a diagnosis of dens evaginatus leading to pulpal necrosis of \#45 with chronic periapical abscess was arrived at.

\section{Treatment}

Root canal treatment was initiated by administering inferior alveolar nerve block using articaine $\mathrm{HCl} 4 \%$ and epinephrine 1:100,000 injection (Septodont, Pennsylvania, USA), followed by single tooth isolation using a rubber dam. Access opening was done using access preparation round ended burs (bur size no. \#2, Dentsply Sirona, Australia). The working length was estimated, and a radiograph was taken to confirm the working length (Fig. 2A). The necrosed pulp was debrided using circumferential filing size $80 \mathrm{~K}$ file, and the canal was thoroughly irrigated with $5.25 \%$ sodium hypochlorite. The wall of the root canal was further cleaned using rispisonic files activated by MM 3000 sonic handpiece (Micro Mega, France). After drying, the canals using paper points UltraCal ${ }^{\mathrm{TM}} \mathrm{XS} 30 \%$ to $35 \%$ calcium hydroxide paste (Ultradent product inc., Utah, USA) was placed as an intracanal medicament, and the access was sealed with Kalzinol (Dentsply Sirona GmbH, Konstanz, Germany).

On the second visit, there was no active discharge from the sinus tract indicating signs of healing (Fig. 2B). The canal was obturated using OrthoMTA (BioMTA, Korea). OrthoMTA was manipulated according to the manufacturer's instructions and carried into the canal using a special carrier and condensed using OrthoMTA plugger. The access was sealed with the composite restoration postoperative IOPA image that was taken (Fig. 2C). Patient was recalled after 6 weeks (Fig. 2D), 6 months (Fig. 2E) and 1-year (Fig. 2F) for a follow-up review during which IOPA radiographs were taken. In addition, at the 1-year follow-up, CBCT (Figs $2 \mathrm{G}$ and $\mathrm{H}$ ) were taken as well.

\section{Discussion}

Dens evaginatus is considered a congenital disorder that can be identified by routine examination. Widely accepted classification for dens evaginatus as given by Oehlers is as follows: ${ }^{9,10}$

- Type I, minor invagination confined to the crown;

- Type II, the invagination extends to and may communicate with the pulp chamber;

- Type IIIA and IIIB, invagination extends beyond cementoenamel junction along the root communicating with the periodontal ligament laterally/at the apical foramen with or without pulpal involvement.

Protruded cusp like morphology on the crown is an important identification clue of this disease. As mandibular premolars are more prone to be affected by this disease, thorough clinical and radiographic investigation of these teeth must be conducted if presence of any tubercle at the occlusal surface of these teeth is detected. However, sometimes affected teeth may not exhibit any symptom of evaginatus malformation, as in the present case. ${ }^{11}$ The present case was identified as a type II dens evaginatus with communication into the pulp canals space. 

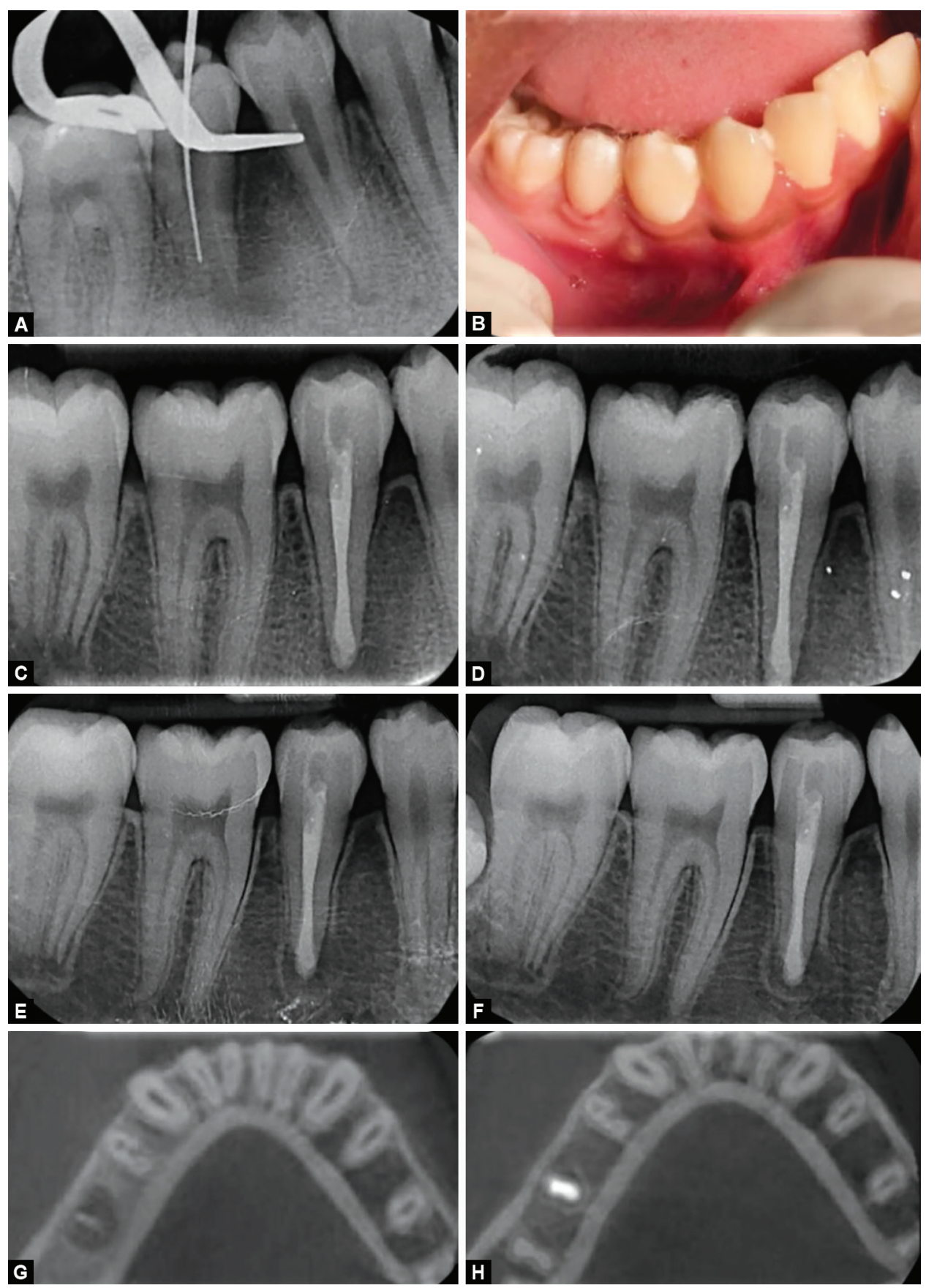

Figs $2 \mathrm{~A}$ to $\mathrm{H}$ : (A) Working length estimation radiograph; (B) Clinical picture of the sinus tract taken during the 2nd visit; (C) Postoperative intraoral periapical (IOPA) radiograph of tooth \#45 on the date; (D) 6th week; (E) 6th month; (F) 12th month of postobturation; (G) Preoperative cone-beam computed tomography $(\mathrm{CBCT})$ scan of tooth \#45; $(\mathrm{H}) 1$ year of postobturation

Cone beam computed tomography is a more effective tool in identifying and treating endodontic problems, as it helps to obtain three-dimensional data of teeth, root canal, and periapical region with lower doses of radiation. ${ }^{12,13}$ Moreover, the successful use of reconstructed $C B C T$ images, especially in assessing the true nature of invagination with communication into the root canal space and periodontal ligament has been reported earlier. ${ }^{14}$ Therefore, in this case, CBCT was used to supplement the information regarding the extent of the periapical lesion and the subsequent healing during the follow-up.

Early diagnosis of dens evaginatus is important as it could offer simplified treatment options to prevent pulp infection such as prophylactic restoration through selective grinding, prophylactic pulp capping, or filling. ${ }^{15,16}$ In the case of pulpal involvement, extraction, intentional replantation, nonsurgical or surgical endodontic treatment, and most recently introduced regenerative endodontic are the other available options. ${ }^{17}$ However, the presence of a chronic periapical lesion, in this case, precluded the regenerative endodontic procedures as a viable treatment option.

The goals of treatment were the elimination of the bacteria from the site of infection and the prevention of further ingress of the pathogens into the periradicular region. In addition, an open apex could increase the complexity of the treatment. ${ }^{5}$ 
In this study, complete disinfection of root canal system was performed by irrigating with $5.25 \%$ sodium hypochlorite supplemented with sonic activation followed by an intracanal placement of $\mathrm{Ca}(\mathrm{OH})_{2}$ sealed with the interim restoration. $\mathrm{Ca}(\mathrm{OH})_{2}$ induces apical and periapical repair by changing the $\mathrm{pH}$ of the root dentine. ${ }^{17,18}$ Hydroxyl ions of the $\mathrm{Ca}(\mathrm{OH})_{2}$ used for intracanal dressing require $2-3$ weeks to diffuse into the outer root dentin and achieve its peak level. ${ }^{19}$ The absence of any signs and symptoms in the first follow-up visit after 6 weeks of treatment indicated a positive effect thorough cleaning and disinfection of the root canal space.

To achieve the second goal, a material that could completely seal the infected root canal in the presence of an open apex with a large periapical radiolucency was needed. Several studies have reported the inability of gutta-percha and/or other commonly used polymer-based root canal obturation materials in obtaining a three-dimensional apical seal. ${ }^{20-23}$

Mineral trioxide aggregate (MTA) due to its sealing ability, biocompatibility, and induced apical healing by inducing the calcified matrix formation in the periapical region, and regeneration of new cementum could be considered as a filling material. ${ }^{10,24,25}$ Studies have also suggested that filling the whole canal with MTA could enhance fracture resistance and root strength. ${ }^{17,26,27}$ However, drawbacks of MTA, such as long setting time, tooth discoloration potential, and handling difficulty, have been reported earlier. ${ }^{28}$ To overcome these drawbacks, many calcium silicate-based cements such as OrthoMTA has been introduced into the market. ${ }^{28}$

Bioceramic materials like OrthoMTA have the antibacterial, bioactive, and regenerative properties in addition to superior sealing activity. ${ }^{21,28}$ Decreased porosity of OrthoMTA is related to its resistance to bacterial leakage since the pore diameter is about $11.1 \mathrm{~nm}$, which is much smaller than that of Enterococcus faecalis, i.e., 0.6-2.5 $\mu \mathrm{m}$. Moreover, orthograde canal obturation with OrthoMTA-PBS paste results in the formation of amorphous and crystalline structures that entombs intratubular bacteria. ${ }^{21}$

In cases of the open apex, it has been suggested to use a barrier such as platelet-rich fibrin (PRF) as an internal matrix against which the MTA can be packed..$^{10}$ In this case, the extent of the infected periapical lesion ruled out the use of an internal matrix. Thus, OrthoMTA without using an internal matrix was chosen as a root canal obturation material. The healing seen in the postoperative IOPA and CBCT images (Figs $2 \mathrm{E}, \mathrm{G}$ and $\mathrm{H}$ ) amply vindicates the potential of the OrthoMTA.

\section{Conclusion}

Management of dens evaginatus in mandibular premolars requires a thorough understanding of the cause and appropriate management that includes effective disinfection and obturation with newer bioceramic materials like OrthoMTA to ensure long-term success and prognosis.

\section{Clinical Significance}

The synergistic effect of the chemomechanical preparation and intracanal medicament, followed by the filling of OrthoMTA helped, in the successful management, of dens evaginatus.

\section{References}

1. Viswanathan S, Nagaraj V, Adimoulame $S$, et al. Dens evaginatus in proximal surface of mandibular premolar: a rare presentation. Case Rep Dent 2012;2012:603583. DOI: 10.1155/2012/603583.
2. Manuja N, Chaudhary S, Nagpal R, et al. Bilateral dens evaginatus (talon cusp) in permanent maxillary lateral incisors: a rare developmental dental anomaly with great clinical significance. BMJ Case Rep 2013;2013:bcr2013009184. DOI: 10.1136/bcr-2013-009184.

3. Lin C-S, Llacer-Martinez M, Sheth CC, et al. Prevalence of premolars with dens evaginatus in a taiwanese and spanish population and related complications of the fracture of its tubercle. Eur Endod J 2018;3(2):118-122. DOI: 10.14744/eej.2018.08208.

4. Echeverri EA, Wang MM, Chavaria C, et al. Multiple dens evaginatus: diagnosis, management, and complications: case report. Pediatr Dent 1994;16(4):314-317.

5. Tsurumachi $\mathrm{T}$, Suguro $\mathrm{H}$, Ogata $\mathrm{H}$, et al. Endodontic treatment of bilateral dens evaginatus premolars with large periapical lesions. J Oral Sci 2009;51(3):475-479. DOI: 10.2334/josnusd.51.475.

6. Levitan ME, Himel VT. Dens evaginatus: literature review, pathophysiology, and comprehensive treatment regimen. J Endod 2006;32(1):1-9. DOI: 10.1016/j.joen.2005.10.009.

7. Borie EE, Oporto VG, Aracena RD. Dens evaginatus in hemophilic patient: a case report. Int J Morphol 2010;28(2):375-378. DOI: 10.4067/ S0717-95022010000200006.

8. Ferraz JA, de Carvalho Júnior JR, Saquy PC, et al. Dental anomaly: dens evaginatus (talon cusp). Braz Dent J 2001;12(2):132-134.

9. Oehlers FA. Dens invaginatus (dilated composite odontome). I. Variations of the invagination process and associated anterior crown forms. Oral Surg Oral Med Oral Pathol 1957;10(11):1204-1218. DOI: 10.1016/0030-4220(57)90077-4 contd.

10. Ali A, Saraf $P$, Patil J. Endodontic management of type IIIB dens invaginatus: an unusual case report. Saudi Endod J 2018;8(2):144-148. DOI: 10.4103/sej.sej_18_17.

11. Shekhar MG, Vijaykumar S, Tenny J, et al. Conservative management of dens evaginatus: report of two unusual cases. Int J Clin Pediatr Dent 2010;3(2):121-124. DOI: 10.5005/jp-journals-10005-1067.

12. Al-Rawi B, Hassan B, Vandenberge B, et al. Accuracy assessment of three-dimensional surface reconstructions of teeth from cone beam computed tomography scans. J Oral Rehabil 2010;37(5):352-358. DOI: 10.1111/j.1365-2842.2010.02065.x.

13. Patel S, Dawood A, Ford TP, et al. The potential applications of cone beam computed tomography in the management of endodontic problems. Int Endod J 2007;40(10):818-830. DOI: 10.1111/j.13652591.2007.01299.x.

14. Vier-Pelisser FV, Morgental RD, Fritscher G, et al. Management of type III dens invaginatus in a mandibular premolar: a case report. Braz Dent J 2014;25(1):73-78. DOI: 10.1590/0103-6440201302351.

15. Hill FJ, Bellis WJ. Dens evaginatus and its management. Br Dent J 1984;156(11):400. DOI: 10.1038/sj.bdj.4805383.

16. Koh ET, Ford TR, Kariyawasam SP, et al. Prophylactic treatment of dens evaginatus using mineral trioxide aggregate. J Endod 2001;27(8): 540-542. DOI: 10.1097/00004770-200108000-00010.

17. Alenazy M, Murwahi A, Altwaijri S, et al. Endodontic management of dens invaginatus of maxillary lateral incisor: report of two cases. Saudi Endod J 2017;7(3):194-198. DOI: 10.4103/1658-5984.213481.

18. Sathorn C, Parashos P, Messer H. Antibacterial efficacy of calcium hydroxide intracanal dressing: a systematic review and meta-analysis. Int Endod J 2007;40(1):2-10. DOI: 10.1111/j.1365-2591.2006.01197.x.

19. Nerwich A, Figdor D, Messer HH. pH changes in root dentin over a 4-week period following root canal dressing with calcium hydroxide. J Endod 1993;19(6):302-306. DOI: 10.1016/S0099-2399(06)80461-9.

20. Punia SK, Nadig P, Punia V. An in vitro assessment of apical microleakage in root canals obturated with gutta-flow, resilon, thermafil and lateral condensation: a stereomicroscopic study. J Conserv Dent 2011;14(2):173-177. DOI: 10.4103/0972-0707.82629.

21. Yoo JS, Chang S-W, Oh SR, et al. Bacterial entombment by intratubular mineralization following orthograde mineral trioxide aggregate obturation: a scanning electron microscopy study. Int J Oral Sci 2014;6(4):227. DOI: 10.1038/ijos.2014.30.

22. Santos J, Tjaderhane L, Ferraz C, et al. Long-term sealing ability of resin-based root canal fillings. Int Endod J 2010;43(6):455-460. DOI: 10.1111/j.1365-2591.2010.01687.x. 
23. Brosco VH, Bernardineli N, Torres SA, et al. Bacterial leakage in obturated root canals-part 2: a comparative histologic and microbiologic analyses. Oral Surg Oral Med Oral Pathol Oral Radiol Endod 2010;109(5):788-794. DOI: 10.1016/j.tripleo.2009.11.036.

24. Demartis $P$, Dessi $C$, Cotti $M$, et al. Endodontic treatment and hypotheses on an unusual case of dens invaginatus. J Endod 2009;35(3):417-421. DOI: 10.1016/j.joen.2008.12.002.

25. Reddy YP, Karpagavinayagam K, Subbarao CV. Management of dens invaginatus diagnosed by spiral computed tomography: a case report. J Endod 2008;34(9):1138-1142. DOI: 10.1016/ j.joen.2008.06.001.
26. Forghani M, Bidar M, Shahrami F, et al. Effect of MTA and Portland cement on fracture resistance of dentin. J Dent Res Dent Clin Dent Prospects 2013;7(2):81-85. DOI: 10.5681/joddd. 2013.014.

27. Bortoluzzi EA, Souza EM, Reis JM, et al. Fracture strength of bovine incisors after intra-radicular treatment with MTA in an experimental immature tooth model. Int Endod J 2007;40(9):684-691. DOI: 10.1111/j.1365-2591.2007.01266.x.

28. Chang SW. Chemical composition and porosity characteristics of various calcium silicate-based endodontic cements. Bioinorg Chem Appl 2018;2018:6. DOI: 10.1155/2018/2784632. 